\title{
Partial Injury to Central Noradrenergic Neurons: Reduction of Tissue Norepinephrine Content Is Greater Than Reduction of Extracellular Norepinephrine Measured by Microdialysis
}

\author{
Elizabeth D. Abercrombie and Michael J. Zigmond \\ Department of Behavioral Neuroscience and Psychiatry, and Center for Neuroscience, University of Pittsburgh, \\ Pittsburgh, Pennsylvania 15260
}

\begin{abstract}
We have examined the impact of partial injury to central noradrenergic terminals on whole tissue norepinephrine (NE) content in hippocampus and on the concentration of $\mathrm{NE}$ and 3,4-dihydroxyphenylacetic acid in extracellular fluid of that structure (using microdialysis perfusion). Partial unilateral depletions of hippocampal tissue NE content were produced by administration of 6-hydroxydopamine $(2-10 \mu \mathrm{g})$ into the dorsal noradrenergic bundle, and 2 weeks later microdialysis probes were placed in hippocampus ipsilateral to the lesion. The resting concentration of NE in hippocampal dialysates was unaffected by the lesion unless the reduction of tissue NE content exceeded $50 \%$. In contrast, the basal concentration of 3,4-dihydroxyphenylacetic acid in hippocampal dialysates declined in proportion to tissue NE content. Tail shock or local perfusion with excess $K$ increased NE in dialysates from sham-lesioned animals and produced equivalent changes in NE in dialysates from animals with moderate $(\leq \mathbf{5 0} \%)$ depletions of tissue NE content. No significant increases of NE in dialysates were observed in response to these stimuli in animals with depletions of tissue NE content greater than $\mathbf{5 0} \%$. To the degree that transmitter level in dialysates is representative of extracellular transmitter concentration, the results suggest that compensatory processes exist by which a normal extracellular concentration of transmitter can be maintained under both basal and stimulated conditions despite the loss of up to one half of a neuronal population. These data also suggest that conclusions concerning the functional impact of a lesion that are based on measurements of the depletion of transmitter content in tissue may not always be valid, since, in the present study, the reduction in tissue content of NE in hippocampus often was considerably larger than the reduction of NE in hippocampal dialysates.
\end{abstract}

\footnotetext{
Received Dec. 8, 1988; revised Apr. 25, 1989; accepted Apr. 25, 1989.

These data were presented, in part, in October 1988 at the Annual Meeting of the American Neurological Association, Philadelphia, and in November 1988 at the Annual Meeting of the Society for Neuroscience, Toronto. This research was funded in part by USPHS grants NS19608 and MH30915. E.D.A. was supported by a Clinical Research Center Grant and Fellowship (MH30915) and by the National Alliance for Research on Schizophrenia and Depression. M.J.Z. was supported by a Research Scientist Award (MH00058).

Correspondence should be addressed to Elizabeth D. Abercrombie, Ph.D., Department of Behavioral Neuroscience, University of Pittsburgh, Pittsburgh, PA 15260.
}

Copyright (C) 1989 Society for Neuroscience $0270-6474 / 89 / 114062-06 \$ 02.00 / 0$
The norepinephrine (NE)-containing neurons of the human locus coeruleus decline in number with age (Vijayashankar and Brody, 1979; Mann et al., 1983; German et al., 1988). In addition, a loss of locus coeruleus neurons occurs in Alzheimer's disease and Parkinson's disease (Hornykiewicz, 1973; Mann et al., 1980; Tomlinson et al., 1981; Iversen et al., 1983; Mann and Yates, 1983; Marcyniuk et al., 1986). Although the precise consequences of these losses remain unknown, evidence points to an important role for noradrenergic mechanisms in cognitive processes (Arnsten and Goldman-Rakic, 1985, 1987; Leslie et al., 1985) and in the response to stress (Korf et al., 1973; Weiss and Simson, 1985; Abercrombie and Jacobs, 1987; Abercrombie et al., 1988).

We wished to determine directly the functional activity of noradrenergic neurons following partial damage to this neuronal population. To do so, we used intracerebral 6-hydroxydopamine (6-HDA) to produce unilateral lesions of the dorsal noradrenergic bundle (Uretsky and Iversen, 1970) and then employed microdialysis as a method to examine NE in the extracellular compartment of hippocampus, a region innervated by this projection. Dihydroxyphenylacetic acid (DOPAC), a metabolite of the NE precursor dopamine, also was examined in dialysates. Measurements of NE and DOPAC in dialysates were made during the resting state and in response to either elevated $\mathrm{K}^{+}$ concentration in the perfusate or tail shock. These latter manipulations were included to assess the ability of NE neurons spared by the lesion to respond to conditions of increased demand. NE in dialysates was related to the tissue NE content of hippocampus, the latter a measure of the extent of terminal degeneration.

\section{Materials and Methods}

Dorsal noradrenergic bundle lesions. Male Sprague-Dawley rats (250$300 \mathrm{gm})$ were anesthetized with chloral hydrate $(400 \mathrm{mg} / \mathrm{kg}$ i.p. $)$ and placed in a stereotaxic instrument (David Kopf Instruments) with skull flat between bregma and lambda. A 30-gauge cannula connected to a 5 $\mu \mathrm{l}$ Hamilton syringe was lowered through a small hole in the skull to the following coordinates: $\mathrm{AP}-5.3, \mathrm{ML} \pm 1.1$ relative to bregma, and DV -5.3 from the dura. Lesioned animals received a $2 \mu \mathrm{l}$ unilateral infusion of a solution containing $1-5 \mathrm{mg} / \mathrm{ml}$ 6-HDA $\mathrm{HBr}$ (Sigma). The vehicle consisted of $1 \mathrm{mg} / \mathrm{ml}$ ascorbic acid in $0.9 \%$ saline. The 6-HDA solution was infused at $0.5 \mu \mathrm{l} / \mathrm{min}$ by means of a microliter syringe pump (Model 341B, Sage Instruments). Sham-operated animals were treated in an identical manner but received $2 \mu \mathrm{l}$ of vehicle alone. All animals were allowed to recover for 2 weeks before being used for dialysis studies.

Dialysis probe construction and implantation. Dialysis loops were constructed from a $1.5 \mathrm{~cm}$ piece of hollow dialysis fiber (Organon Teknika Corp.) as previously described (Abercrombie et al., 1988). Briefly, 
each end of the dialysis tubing was threaded into a length of polyethylene tubing (PE-10, Clay Adams) and glued into place. A length of fused silica glass capillary tubing (120 $\mu \mathrm{m}$ ID and $170 \mu \mathrm{m}$ OD, Alltech) was glued into one piece of the PE tubing and served as the outlet line. The dialysis fiber was bent into a loop, the active portion of which was 2.5 $\mathrm{mm}$ in vertical distance.

To determine relative recovery, each probe was suspended in a beaker of artificial cerebrospinal fluid (CSF; composition $147 \mathrm{~mm} \mathrm{NaCl}, 3.9$ $\mathrm{mm} \mathrm{KCl}$, and $2.3 \mathrm{~mm} \mathrm{CaCl}$, pH 6.0) to which NE and DOPAC had been added at concentrations of $0.5 \mu \mathrm{M}$, and the concentration of NE and DOPAC obtained in the dialysate was measured. The mean relative recovery for probes used in the present experiments was $20 \pm 1 \%$ for NE and $19 \pm 1 \%$ for DOPAC.

The probes were implanted as previously described (Abercrombie et al., 1988) into the dentate gyrus of the dorsal hippocampus ipsilateral to the lesion (coordinates: $\mathrm{AP}-3.8, \mathrm{ML} \pm 2.0$ relative to bregma, and DV -3.8 from the dura). Artificial CSF was continuously perfused through the probe at $1.5 \mu \mathrm{l} / \mathrm{min}$ via a fluid swivel (Spalding Medical Products) that permitted relatively unrestricted movement of the animal.

The animal was allowed to recover for approximately $16 \mathrm{hr}$ before measurements were begun, and all experiments were conducted during the first $2 \mathrm{~d}$ after implantation. Dialysis samples were collected at 15 min intervals in plastic vials. Before initiating any experimental manipulation, $\mathrm{NE}$ in dialysates was monitored for at least $1 \mathrm{hr}$ to ensure a stable baseline. Each animal participated in all experimental conditions. The presentation order of the conditions was counterbalanced, and no order effects were detected (unpaired $t$-test).

Experimental manipulations. Local depolarization was effected by switching the perfusate from standard CSF containing $3.9 \mathrm{mM} \mathrm{KCl}$ to artificial CSF containing $60 \mathrm{~mm} \mathrm{KCl}$ for $1 \mathrm{hr}$ (the $\mathrm{NaCl}$ concentration of the CSF was reduced to $91 \mathrm{~mm}$ to maintain physiological osmolarity). Tail shock ( $1 \mathrm{~mA})$ was delivered intermittently for $30 \mathrm{~min}$ as previously described (Abercrombie et al., 1988).

Analysis of NE and DOPAC in dialysates. The dialysate was analyzed using HPLC coupled with electrochemical detection with minor modification of previously published methods (Abercrombie et al., 1988). Briefly, a Velosep RP- 18 column $(100 \times 3.2 \mathrm{~mm}, 3 \mu \mathrm{m}$, Brownlee Labs) was used together with a mobile phase consisting of $80 \mathrm{~mm}$ sodium phosphate buffer $\mathrm{pH} 2.75,100 \mu \mathrm{M}$ EDTA, $1.0 \mathrm{~mm}$ sodium octylsulfate, and $5 \%(\mathrm{vol} / \mathrm{vol})$ methanol. The flow rate through the system was 700 $\mu 1 / \mathrm{min}$. Electrochemical detection was accomplished with an ESA Coulochem model $5100 \mathrm{~A}$ detector operated in differential mode. The potential of the conditioning (oxidizing) cell was set at $+0.40 \mathrm{~V}$, the first (reductive screen) detector cell at $+0.06 \mathrm{~V}$, and the potential of the second (reducing) detector cell at $-0.26 \mathrm{~V}$.

Determination of tissue catecholamine content. One to $2 \mathrm{~d}$ after the conclusion of the experiments, animals were killed by decapitation, the dialysis probe assembly removed, and the hippocampus and striatum rapidly dissected out on ice. Placement of the dialysis probe in the hippocampus was verified by visual inspection, and tissues then were frozen for future analysis. Subsequently, tissue samples were weighed and homogenized in $0.1 \mathrm{~N}$ perchloric acid containing $100 \mu \mathrm{M}$ EDTA, followed by centrifugation at $34,800 \mathrm{~g}$ for $10 \mathrm{~min}$ at $2-4^{\circ} \mathrm{C}$. Samples of the supernatant were directly analyzed by HPLC using standard procedures (Keller et al., 1976; Mefford, 1981).

Data analysis. NE and DOPAC in dialysates were expressed as picograms of the compound per $25 \mu \mathrm{l}$ of dialysate. Tissue catecholamine content was expressed as nanograms per gram wet weight. Depletion of NE in hippocampal tissue ipsilateral to the lesion then was cxpresscd as a percentage of the intact, contralateral side. Data are presented as mean \pm SEM of the results obtained from groups of $n$ animals. Data were grouped a posteriori according to percentage depletion of hippocampal NE content and analyzed using repeated measures analysis of variance coupled with the Neuman-Keuls multiple comparisons test. The level of significance for all analyses was set at $p<0.05$.

\section{Results}

\section{Tissue catecholamine content}

Administration of 2-10 $\mu \mathrm{g}$ of 6-HDA produced significant depletions of hippocampal tissue NE content, which ranged from $20 \%$ to greater than $95 \%$ (Table 1). In sham-lesioned animals receiving vehicle alone, tissue NE content in the intact hippo-
Table 1. Norepinephrine levels in hippocampal tissue following unilateral partial dorsal noradrenergic bundle lesion

\begin{tabular}{lllll} 
& & & \multicolumn{2}{c}{ Hippocampal NE } \\
\cline { 3 - 4 } Group & Side & $n$ & $\begin{array}{l}\text { ng/g wet } \\
\text { weight }\end{array}$ & $\begin{array}{l}\% \\
\text { depletion }\end{array}$ \\
\hline Sham & Intact & 6 & $360 \pm 35$ & - \\
& Operated & & $356 \pm 33$ & \\
$<50 \%$ & Intact & 6 & $393 \pm 25$ & 35 \\
$50-90 \%$ & Lesion & & $293 \pm 14^{a}$ & \\
& Intact & 8 & $387 \pm 25$ & 75 \\
& Lesion & & $92 \pm 15^{a}$ & \\
& Intact & 6 & $435 \pm 44$ & 95 \\
& Lesion & & $25 \pm 10^{a}$ & \\
\hline
\end{tabular}

Data are mean \pm SEM.

${ }^{a} p<0.05$, paired $t$-test.

campus $(360 \pm 35 \mathrm{ng} / \mathrm{gm})$ was not significantly different from that on the operated side $(356 \pm 33 \mathrm{ng} / \mathrm{gm})$. No significant effects of this lesion procedure on striatal tissue dopamine content were observed (data not shown).

\section{$N E$ and DOPAC in dialysates as a function of tissue $N E$ depletion}

The administration of 6-HDA into the dorsal noradrenergic bundle had a significant effect on NE levels in hippocampal dialysates $[F(3,22)=25.53, p<0.01]$. In sham-lesioned animals, the resting level of NE in dialysates was $10 \pm 2$ pg per sample. This value was not significantly different from that of animals with reductions of tissue NE content of $50 \%$ or less (11 \pm 1 pg per sample). In contrast, NE in dialysates was significantly lower in animals sustaining depletions of tissue NE content greater than $50 \%$ compared to sham-lesioned animals. However, in these animals, the NE in dialysates was always above the level that would be predicted by a perfect relation between NE in dialysate and tissue NE content (Fig. 1). Taken together, these data were best fit by a second-order polynomial equation using the method of least squares $(r=0.88, p<0.001)$.

The basal level of DOPAC in hippocampal dialysates also was significantly affected by the lesions $[F(3,22)=27.08, p<$ $0.01]$. DOPAC in dialysates proved to be linearly correlated with tissue NE content $(r=0.90, p<0.001)$. The line of best fit for these data was virtually identical to the line depicting a perfect relation between DOPAC in dialysate and tissue NE depletion (Fig. 2). In sham-lesioned animals, the basal level of DOPAC in dialysates was $24 \pm 2 \mathrm{pg}$ per sample. This value was significantly greater than that obtained in animals sustaining depletions of tissue NE content less than or equal to $50 \%$ (15 \pm 2 pg per sample) as well as in animals with even larger levels of tissue NE depletion.

\section{Effects of elevated $\mathrm{K}^{+}$and tail shock on $N E$ in dialysates}

Increasing the $\mathrm{K}^{+}$concentration of the artificial CSF perfusate had a significant effect on NE in hippocampal dialysates $[F(1,22)$ $=113.92, p<0.01]$, which varied according to the degree of reduction of NE content in hippocampal tissue $[F(3,22)=24.03$, $p<0.01]$. The stimulus produced comparable effects in shamlesioned animals $(+197 \%)$ and animals with less than $50 \%$ reduction of tissue NE content $(+185 \%)$. In contrast, animals sustaining tissue NE depletions of $50 \%$ or greater showed no 
Figure 1. The absolute amounts of NE obtained in hippocampal dialysates as a function of the percentage depletion of tissue NE content in hippocampus. Left, Data in groups, selected a posteriori, sustaining comparable levels of tissue NE depletion. NE levels in dialysates from sham-lesioned animals and animals with less than $50 \%$ tissue NE depletion were not significantly different. The absolute level of NE in dialysates did decline at higher levels of depletion. Right, Individual animal data points. These data were best fit by a second-order polynomial equation using the method of least squares (solid line, $r=0.88$ ). The dashed line represents the hypothetical relation in which decreases in tissue NE content are accompanied by proportional decreases in dialysate $\mathrm{NE}$.

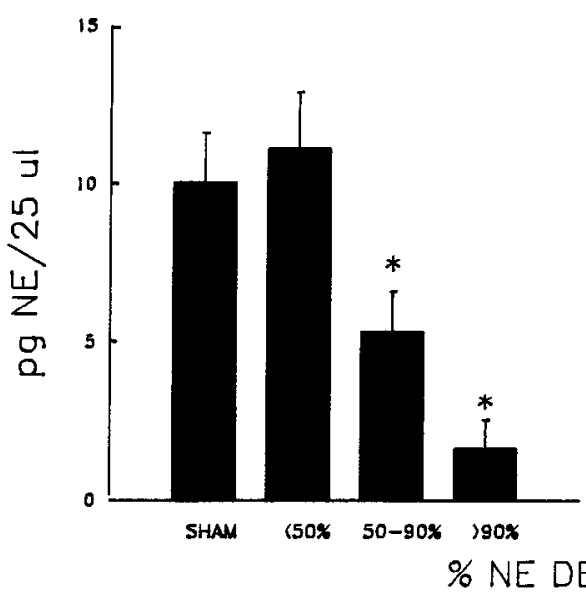

$\%$ NE DEPLETION

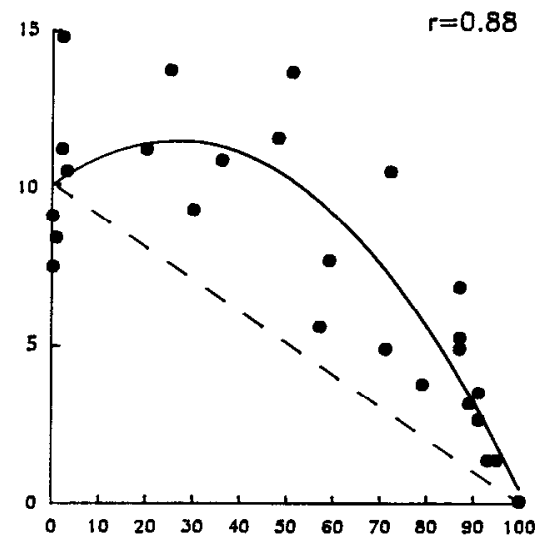

Tail shock also produced a significant effect on DOPAC in dialysates $[F(1,22)=46.21, p<0.01]$, which was dependent on the extent of the reduction in tissue NE content $[F(3,22)=$ $12.71, p<0.01]$. In animals with tissue NE depletions of $50 \%$ or less, stress produced a $95 \%$ elevation in DOPAC in dialysates. Again, however, no significant stress-induced changes in DOPAC were observed in dialysates from sham-lesioned animals or in dialysates from animals with more than $90 \%$ depletion of hippocampal NE content (Fig. 4).

\section{Discussion}

The present study demonstrates that the basal concentration of NE in hippocampal dialysates remains normal despite 6-HDAinduced depletions of tissue NE content of up to $50 \%$. With still greater loss of tissue NE content, NE in dialysates was reduced. Even in these latter animals, however, the NE in dialysates under basal conditions was nearly 3 -fold higher than would have been predicted if $\mathrm{NE}$ in dialysate declined in direct proportion to $\mathrm{NE}$ in tissue (Fig. 1).

We believe these results indicate that after the partial degeneration of central noradrenergic terminals, those terminals that remain are able to maintain the extracellular concentration of $\mathrm{NE}$ at a normal level. This interpretation is based on several assumptions. First, it is assumed that the loss of NE content in
Figure 2. The absolute amounts of DOPAC obtained in hippocampal dialysates as a function of the percentage depletion of tissue NE content in hippocampus. Left, Grouped data. DOPAC levels in dialysates declined as a function of tissue NE depletion. Right, Individual animal data points. The data reveal a linear correlation between DO$\mathrm{PAC}$ in dialysate and tissue NE depletion (solid line, $r=0.90$ ) that is virtually identical to a perfect relation between these variables (dashed line).

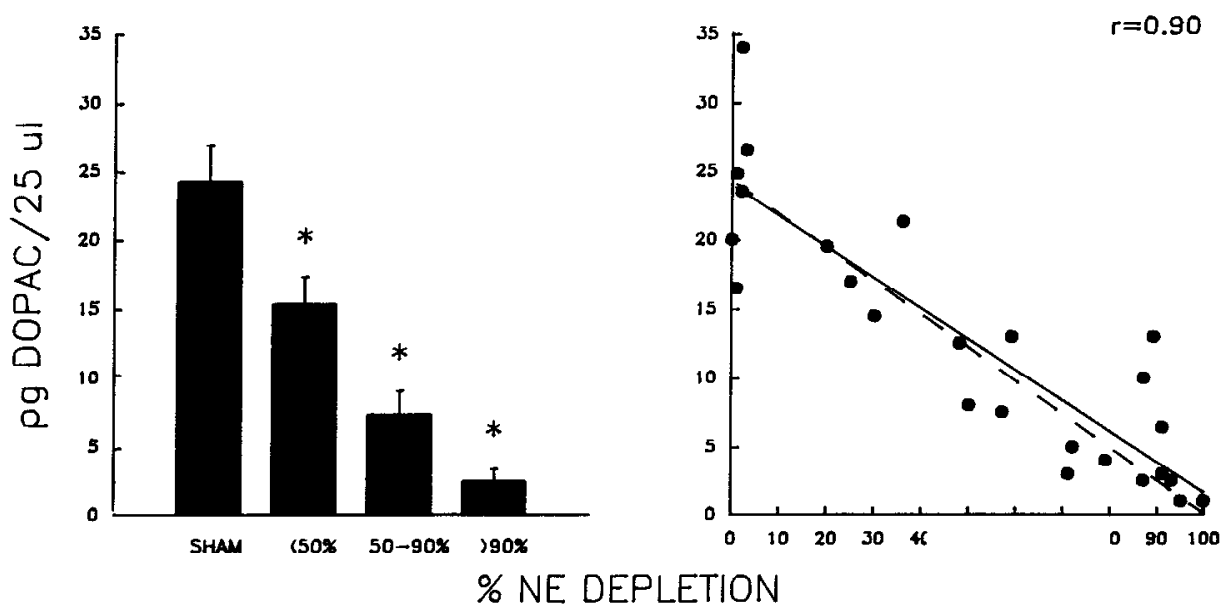




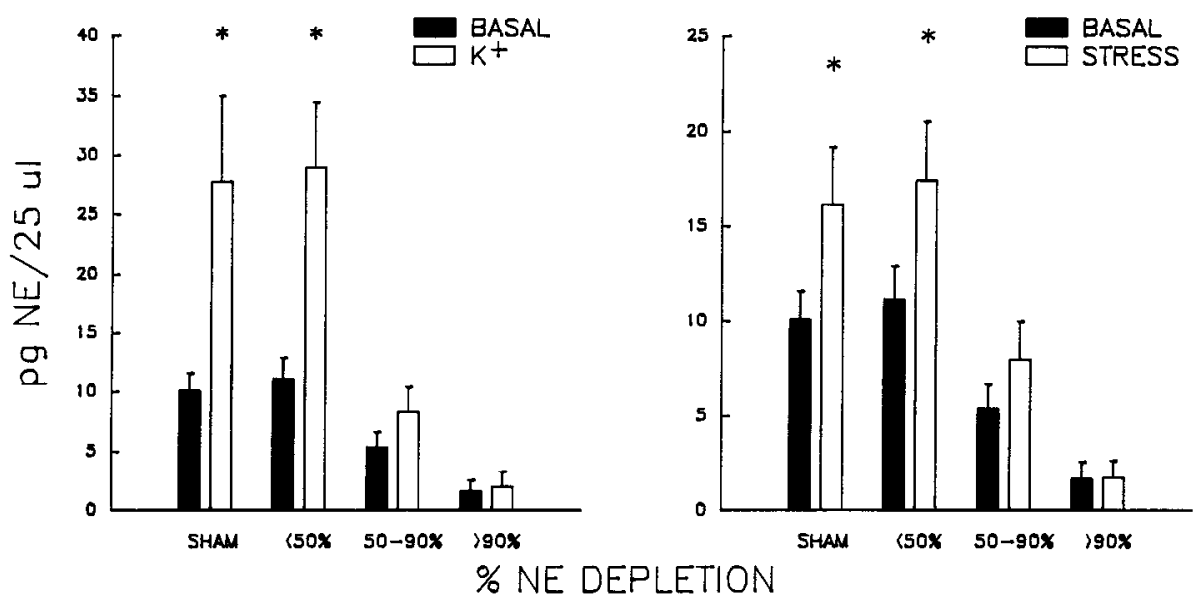

Figure 3. Effects of increased $\mathrm{K}^{+}$in the perfusate $(l e f t)$ and stress $(r i g h t)$ on NE amounts in hippocampal dialysates obtained from animals grouped a posteriori according to percentage depletion of hippocampal tissue NE content. The marked increases in NE in dialysates produced by these stimuli were not significantly different among shamlesioned animals and animals with less than $50 \%$ tissue NE depletion. In animals sustaining larger tissue NE depletions, no significant changes in dialysate NE were observed in response to these stimuli. the entire hippocampus reflects the loss in the region of the probe. Second, we assume that the reduction of tissue NE content is proportional to the extent of noradrenergic terminal degeneration. This assumption is based on the common observation that after partial lesions of a catecholamine-containing system, the transmitter content of the affected tissue is reduced by an amount proportional to the loss of other specific biochemical indices, such as high-affinity catecholamine uptake and the initial $\mathrm{V}_{\max }$ for tyrosine hydroxylase (Zigmond et al., 1971, 1984; Sachs and Jonsson, 1972; Lidbrink and Jonsson, 1974). The third assumption made is that the amount of NE present in the dialysate reflects the general concentration of NE in extracellular fluid. There is at present no way in which to test this proposition directly. However, it has been shown by several groups that when catecholamine concentrations are monitored by dialysis, alterations in response to pharmacological or environmental manipulations generally are consistent with predictions made from more conventional measurements of neuronal activity (L'Heureux et al., 1986; Westerink et al., 1987, 1988).

Since high-affinity uptake into noradrenergic terminals is thought to be a major factor in the clearance of NE from the synapse, degeneration of a significant number of those terminals may increase the extent of NE overflow into extracellular fluid. Thus, the maintenance of a normal extracellular concentration of NE despite the considerable loss of NE terminals could be a passive consequence of the degenerative process. However, we previously have shown that inclusion in the perfusate of desipramine $(1 \mu \mathrm{M})$, an inhibitor of NE uptake, does not have a marked effect on the concentration of $\mathrm{NE}$ in dialysate under resting conditions, although a significant effect is observed under activating situations (Abercrombie et al., 1988). This suggests that, even in the intact hippocampus, a large proportion of $\mathrm{NE}$ escapes from the synapse to diffuse relatively freely in the extracellular space. Thus, the loss of high-affinity reuptake sites, although perhaps contributing to the observed maintenance of normal extracellular NE, would not appear to account cntircly for our results.

An additional consideration relevant to our results is that more NE is being released from each remaining terminal. Two previous observations from this laboratory support this interpretation. First, we have shown that subtotal destruction of central noradrenergic neurons results in significant increases in the ratio of tyrosine hydroxylase activity to tissue NE content, suggesting that residual noradrenergic neurons increase synthesis of NE in response to the injury (Acheson and Zigmond, 1981; Fluharty et al., 1984; see also Gage et al., 1983). Furthermore, we have observed that the firing rate of locus coeruleus neurons appears to be elevated in noradrenergic neurons surviving injury (Chiodo et al., 1983).

$\mathrm{NE}$ levels in dialysates from animals with moderate reductions of tissue NE content appeared normal during conditions

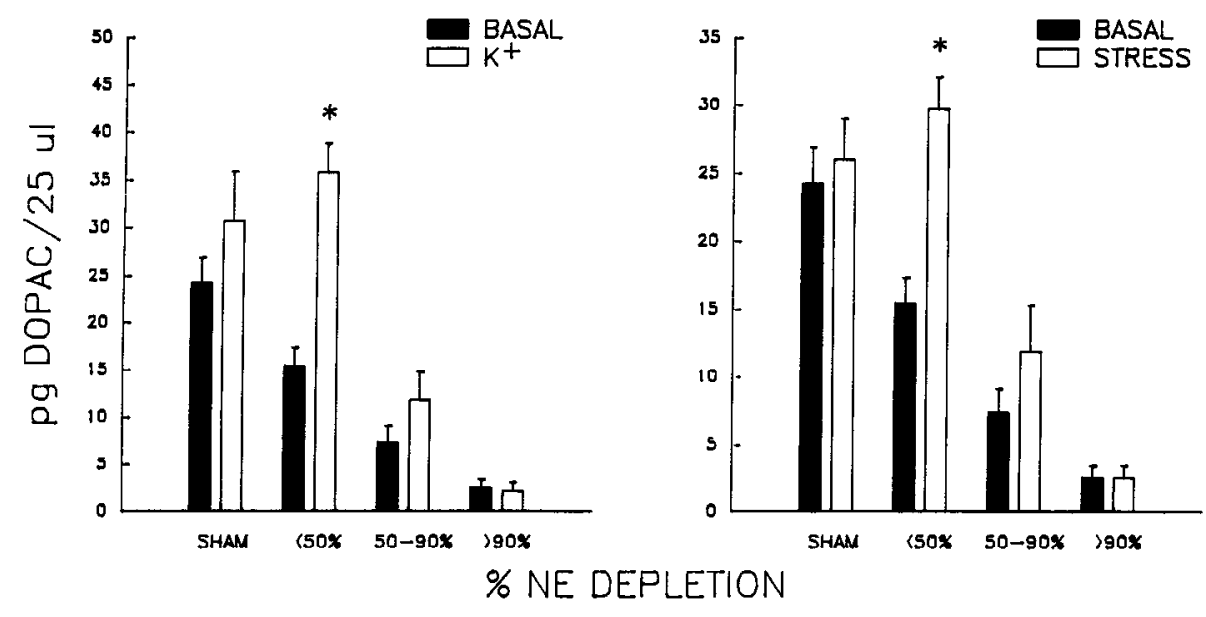

Figure 4. Effects of increased $\mathrm{K}^{+}$in the perfusate (left) and stress (right) on DOPAC amounts in hippocampal dialysates obtained from animals grouped a posteriori according to percentage depletion of hippocampal tissue NE content. A significant increase in DOPAC in dialysates was observed only in those animals with the lowest levels of tissue NE depletion (20-50\%). 
of increased demand as well as in the resting state. Thus, the increases in NE in dialysates that were observed in response to elevated $\mathrm{K}^{+}$or tail shock in sham-lesioned animals also were noted in animals with up to $50 \%$ loss of tissue NE content. In contrast, when tissue NE depletions exceeded $50 \%$, no significant stimulation-induced changes in dialysate NE were observed. These findings suggest that the combination of a large lesion and increased environmental demand exceeds the capacity of residual neurons to maintain extracellular NE at a normal level, thereby indicating the limits of the compensatory processes available to the system (see also Kalén et al., 1988).

Additional support for the these hypotheses comes from studies of the nigrostriatal dopamine system, where the behavioral consequences of the degenerative process are more overt. Although animals sustaining extensive injury to this system display gross neurological deficits, few permanent behavioral deficits are observed in the resting state unless the loss of tissue dopamine content exceeds $95 \%$. On the other hand, neurological symptoms can be induced under conditions of severe stress in such animals (Stricker and Zigmond, 1976; Marshall, 1979). There is now a considerable body of evidence to suggest that these phenomena reflect compensatory changes occurring in the remaining dopaminergic neurons (for reviews see Zigmond and Stricker, 1974, 1985). Such changes include elevated rates of transmitter synthesis and release (Sharman et al., 1967; Agid et al., 1973; Bernheimer et al., 1973; Hefti et al., 1980; Zigmond et al., 1984; Robinson and Whishaw, 1988; Zhang et al., 1988), as well as decreased reuptake of released transmitter (Zigmond et al., 1984; Altar et al., 1987; Stachowiak et al., 1987). These compensations appear to be adequate to maintain a normal level of dopaminergic function in the resting state despite extensive neuronal degeneration but are inadequate under extreme conditions of stress.

It is not yet possible to determine whether any adaptive function is served by the apparent ability of locus coeruleus to maintain extracellular NE concentration constant under basal conditions and during stress despite partial injury. However, it is noteworthy that lesion-induced increases in $\beta$-adrenergic receptors do not occur unless depletions of tissue NE exceed $90 \%$ (Dunwiddie et al., 1983; Zahniser et al., 1986; Dooley et al., 1987), suggesting that presynaptic compensations are able to provide adequate stimulation of target cells until lesions become extremely large. Likewise, it has been shown that several weeks after dorsal noradrenergic bundle lesion, the electrophysiological characteristics of hippocampal cells are normal despite a persistent reduction in the NE content of that tissue (Dunwiddie et al., 1983; Zahniser et al., 1986).

In contrast to our observation of an increase in the ratio of basal NE in dialysates to tissue NE content after partial injury, the relation between basal DOPAC in dialysates and tissue NE content remained constant. This may indicate that DOPAC, which is a principal metabolite of dopamine, actually derives primarily from noradrenergic neurons as a by-product of transmitter synthesis (Bradberry et al., 1986; Eisenhofer et al., 1988). Consistent with this interpretation is the observation that there is no significant dopaminergic innervation of the dentate gyrus, although a small dopaminergic innervation of other hippocampal regions has been described (Verney et al., 1985). Furthermore, tissue dopamine level in striatum was not significantly affected in the present studies, suggesting that dopaminergic afferents to the forebrain remained intact (data not shown). Extracellular DOPAC in this region of hippocampus, therefore, may reflect the balance between the rate of synthesis of dopamine in NE nerve terminals and the rate of transport of that dopamine into NE storage vesicles. The mechanisms underlying regulation of this hypothesized balance are not easily elucidated based on the present data. Clearly, a determination of the mechanism of these phenomena will require further investigation.

In summary, the data of the present study demonstrate that the amount of damage in central catecholamine systems as assessed by measurement of tissue content is not predictive of the concentration of transmitter in the extracellular fluid as measured by microdialysis. Thus, caution must be used in interpreting findings based on tissue transmitter levels, since these levels may not accurately reflect the level of transmitter in the extracellular space. It also is tempting to speculate, based on these observations, that a lifetime of normal neuronal deterioration, such as is known to occur in central catecholaminergic systems, may never result in adverse functional consequences. The acceleration of the normal process of neuronal loss by disease, however, may cause the system involved to reach the point where satisfactory compensation no longer occurs and neurological impairment ensues.

\section{References}

Abercrombie, E. D., and B. L. Jacobs (1987) Single-unit response of noradrenergic neurons in the locus coeruleus of freely moving cats. I. Acutely presented stressful and nonstressful stimuli. J. Neurosci. 7: 2837-2843.

Abercrombie, E. D., and M. J. Zigmond (1988) Hippocampal NE and DOPAC release following damage to the dorsal bundle: Dialysis studies. Soc. Neurosci. Abstr. 14: 740.

Abercrombie, E. D., R. W. Keller, and M. J. Zigmond (1988) Characterization of hippocampal norepinephrine release as measured by microdialysis perfusion: Pharmacological and behavioral studies. Neuroscience 27: 897-904.

Acheson, A. L., and M. J. Zigmond (1981) Short and long term changes in tyrosine hydroxylase activity in rat brain after subtotal destruction of central noradrenergic neurons. J. Neurosci. 1: 493-504.

Agid, Y., F. Javoy, and J. Glowinski (1973) Hyperactivity of DA neurons after partial destruction of nigrostriatal DA system. Nature 245: $150-151$.

Altar, C. A., M. R. Marien, and J. F. Marshall (1987) Time course of adaptations in dopamine biosynthesis, metabolism, and release following nigrostriatal lesions: Implications for behavioral recovery from brain injury. J. Neurochem. 48: 390-399.

Arnsten, A. F. T., and P. S. Goldman-Rakic (1985) Alpha-2-adrenergic mechanisms in prefrontal cortex associated with cognitive decline in aged nonhuman primates. Science 230: 1273-1276.

Arnsten, A. F. T., and P. S. Goldman-Rakic (1987) Noradrenergic mechanisms in age-related cognitive decline. J. Neural Trans. 24: 317-324.

Bernheimer, H., W. Birkmayer, O. Hornykiewicz, K. Jellinger, and F. Seitelberger (1973) Brain dopamine and the syndromes of Parkinson and Huntington: Clinical, morphological, and neurochemical correlations. J. Neurol. Sci. 20: 415-455.

Bradberry, C. W., M. P. Brazell, and R. N. Adams (1986) In vivo dialysis measurements in rat thalamus: Effects of the alpha-adrenergic antagonist yohimbine. Soc. Neurosci. Abstr. 12: 1465.

Chiodo, L. A., A. L. Acheson, M. J. Zigmond, and E. M. Stricker (1983) Subtotal destruction of central noradrenergic projections increases the firing rate of locus coeruleus cells. Brain Res. 264: 123-126.

Dooley, D. J., G. H. Jones, and T. W. Robbins (1987) Noradrenalineand time-dependent changes in neocortical alpha $a_{2}$-and beta $a_{1}$-adrenoceptor binding in dorsal noradrenergic bundle-lesioned rats. Brain Res. 420: 152-156.

Dunwiddie, T. V., A. L. Mueller, P. C. Bickford, and N. R. Zahniser (1983) Electrophysiological and biochemical sequelae of the destruction of hippocampal noradrenergic afferents by DSP4. Brain Res. 269: 311-317.

Eisenhofer, G., D. S. Goldstein, T. G. Ropchak, and I. J. Kopin (1988) 
Source and physiological significance of plasma 3,4-dihydroxyphenylalanine in the rat. J. Neurochem. 51: 1204-1213.

Fluharty, S. J., E. M. Stricker, and M. J. Zigmond (1984) Partial damage to the noradrenergic bundle increases tyrosine hydroxylase activity in noradrenergic terminals of hippocampus but not cerebellum. Brain Res. 324: 390-393.

Gage, F. H., A. Bjorklund, and U. Stenevi (1983) Local regulation of compensatory noradrenergic hyperactivity in the partially denervated hippocampus. Nature 303: 819-821.

German, D. C., B. S. Walker, K. Manaye, W. K. Smith, D. J. Woodward, and A. J. North (1988) The human locus coeruleus: Computer reconstruction of cellular distribution. J. Neurosci. 8: 1776-1788.

Hefti, F., E. Melamed, and R. J. Wurtman (1980) Partial lesions of the nigrostriatal system in rat brain: Biochemical characterization. Brain Res. 195: 123-137.

Hornykiewicz, O. (1973) Parkinson's disease: From brain homogenate to treatment. Fed. Proc. 32: 183-190.

Iversen, L. L., M. N. Rossor, G. P. Reynolds, R. Hills, M. Roth, C. Q. Mountjoy, S. L. Foote, J. H. Morrison, and F. E. Bloom (1983) Loss of pigmented dopamine-B-hydroxylase positive cells from locus coeruleus in senile dementia of Alzheimer's type. Neurosci. Lett. 39:95100.

Kalén, P., M. Kokaia, O. Lindvall, and A. Björklund (1988) Basic characteristics of noradrenaline release in the hippocampus of intact and 6-hydroxydopamine lesioned rats as studied by in vivo microdialysis. Brain Res. 474: 374-379.

Keller, R., A. Oke, I. Mefford, and R. Adams (1976) Liquid chromatographic analysis of catecholamines: Routine assay for regional brain mapping. Life Sci. 19: 995-1004.

Korf, J., G. K. Aghajanian, and R. H. Roth (1973) Increased turnover of norcpinephrine in the rat cerebral cortex during stress: Role of the locus coeruleus. Neuropharmacology 12: 933-938.

Leslie, F. M., S. E. Loughlin, D. B. Sternberg, J. L. McGaugh, L. E. Young, and S. F. Zornetzer (1985) Noradrenergic changes and memory loss in aged mice. Brain Res. 359: 292-299.

L'Heureux, R., T. Dennis, O. Curet, and B. Scatton (1986) Measurement of endogenous noradrenaline release in the rat cerebral cortex in vivo by transcortical dialysis: Effects of drugs affecting noradrenergic transmission. J. Neurochem. 46: 1794-1801.

Lidbrink, P., and G. Jonsson (1974) Noradrenaline nerve terminals in the cerebral cortex: Effects on noradrenaline uptake and storage following axonal lesion with 6 -hydroxydopamine. J. Neurochem. 22 : 617-626.

Mann, D. M. A., and P. O. Yates (1983) Pathological basis for neurotransmitter changes in Parkinson's disease. Neuropathol. Appl. Neurobiol. 9: 3-19.

Mann, D. M. A., J. Lincoln, P. O. Yates, J. E. Stamp, and S. Toper (1980) Changes in the monoamine-containing neurones of the human CNS in senile dementia. Br. J. Psychiatry 136: 533-541.

Mann, D. M. A., P. O. Yates, and J. Hawkes (1983) The pathology of the human locus coeruleus. Clin. Neuropathol. 2: 1-7.

Marcyniuk, B., D. M. A. Mann, and P. O. Yates (1986) Loss of nerve cells from locus coeruleus in Alzheimer's disease is topographically arranged. Neurosci. Lett. 64: 247-252.

Marshall, J. F. (1979) Somatosensory inattention after dopaminedepleting intracerebral 6-OHDA injections: Spontaneous recovery and pharmacological control. Brain Res. 177: 311-324.

Mefford, I. N. (1981) Application of high-performance liquid chromatography with electrochemical detection to neurochemical analysis: Measurement of catecholamines, serotonin and metabolites in rat brain. J. Neurosci. Methods 3: 207-224.

Robinson, T. E., and I. Q. Whishaw (1988) Normalization of extracellular dopamine in striatum following recovery from a partial unilateral 6-OHDA lesion of the substantia nigra: A microdialysis study in freely moving rats. Brain Res. 450: 209-224.

Sachs, C., and G. Jonsson (1972) Selective 6-hydroxy-DOPA induced degeneration of central and peripheral noradrenaline neurons. Brain Res. 40: 563-568.
Sharman, D. F., L. J. Poirier, G. F. Murphy, and T. L. Sourkes (1967) Homovanillic acid and dihydroxyphenylacetic acid in the striatum of monkeys with brain lesions. Can. J. Physiol. Pharmacol. 45: 5762.

Stachowiak, M. K., R. W. Keller, E. M. Stricker, and M. J. Zigmond (1987) Increased dopamine efflux from striatal slices during development and after nigrostriatal bundle damage. J. Neurosci. 7: 16481654.

Stricker, E. M., and M. J. Zigmond (1976) Recovery of function following damage to central catecholamine-containing neurons: A neurochemical model for the lateral hypothalamic syndrome. In Progress in Physiological Psychology and Psychobiology, Vol. 6, J. M. Sprague and A. N. Epstein, eds., pp. 121-188, Academic, New York.

Tomlinson, B. E., D. Irving, and G. Blessed (1981) Cell loss in the locus coeruleus in senile dementia of Alzheimer type. J. Neurol. Sci. 49: 419-428.

Uretsky, N. J., and L. L. Iversen (1970) Effects of 6-hydroxydopamine on catecholamine-containing neurones in the rat brain. J. Neurochem. 17: 269-278.

Verney, C., M. Baulac, B. Berger, C. Alvarez, A. Vigny, and K. B. Helle (1985) Morphological evidence for a dopaminergic terminal field in the hippocampal formation of young and adult rat. Neuroscience 14 : 1039-1052.

Vijayashankar, N., and H. Brody (1979) A quantitative study of the pigmented neurons in the nuclei locus coeruleus and subcoeruleus in man as related to aging. J. Neuropathol. Exp. Neurol. 38: 490-497.

Weiss, J. M., and P. G. Simson (1985) Neurochemical basis of stressinduced depression. Psychopharmacol. Bull. 21: 447-457.

Westerink, B. H. C., J. Tuntler, G. Damsma, H. Rollema, and J. B. de Vries (1987) The use of tetrodotoxin for the characterization of drugenhanced dopamine relcase in conscious rats studicd by brain dialysis. Naunyn Schmiedebergs Arch. Pharmacol. 336: 502-507.

Westerink, B. H. C., H. M. Hofsteede, G. Damsma, and J. B. de Vries (1988) The significance of extracellular calcium for the release of dopamine, acetylcholine and amino acids in conscious rats, evaluated by brain microdialysis. Naunyn Schmiedebergs Arch. Pharmacol. 337: 373-378.

Zahniser, N. R., G. R. Weiner, T. Worth, K. Philpott, R. P. Yasuda G. Jonsson, and T. V. Dunwiddie (1986) DSP4-induced noradrenergic lesions increase $\beta$-adrenergic receptors and hippocampal electrophysiological responsiveness. Pharmacol. Biochem. Behav. 24: 1397-1402.

Zhang, W. Q., H. A. Tilson, K. P. Nanry, P. M. Hudson, J. S. Hong, and M. K. Stachowiak (1988) Increased dopamine release from striata of rats after unilatcral nigrostriatal bundlc damage. Brain Rcs. 461: $335-342$.

Zigmond, M. J., and E. M. Stricker (1974) Ingestive behavior following damage to central dopamine neurons: Implications for homeostasis and recovery of function. In Neuropsychopharmacology of Monoamines and Their Regulatory Enzymes, E. Usdin, ed., pp. 385-402, Raven, New York.

Zigmond, M. J., and E. M. Stricker (1985) Adaptive properties of monoaminergic neurons. In Handbook of Neurochemistry, Alterations of Metabolites in the Nervous System, Vol. 9, A. Lajtha, ed., pp. 87102, Plenum, New York.

Zigmond, M. J., J. P. Chalmers, J. R. Simpson, and R. J. Wurtman (1971) Effect of lateral hypothalamic lesions on uptake of norepinephrine by brain homogenates. J. Pharmacol. Exp. Ther. 179: 2028.

Zigmond, M. J., A. L. Acheson, M. K. Stachowiak, and E. M. Stricker (1984) Neurochemical compensation after nigrostriatal bundle injury in an animal model of preclinical parkinsonism. Arch. Neurol. 41: 856-861. 